\title{
근육경직의 약물치료
}

\section{고 은 재·김 대 열}

울산대학교 의과대학 서울아산병원 재활의학과

\section{Pharmacological management of muscle spasticity}

Eun Jae Ko, MD · Dae-Yul Kim, MD

Department of Rehabilitation Medicine, Asan Medical Center, University of Ulsan College of Medicine, Seoul, Korea

Background: Muscle spasticity is a neurologic disorder, which is considered one of the positive signs of upper motor neuron diseases. Spasticity is common after brain or spinal cord injury. Since spasticity results in tendon retraction, muscle weakness, pain, ankylosis, and disability in activities of daily living, treatment is warranted. Current Concepts: Spasticity is usually assessed using the Modified Ashworth Scale or Modified Tardieu Scale. It is treated with various methods, including physical therapy, occupational therapy, orthosis, medication, and surgery. Pharmacological management should be selected according to the location and severity of the symptom and includes oral medications, chemical nerve block, and intrathecal baclofen pump insertion. Oral medications include baclofen, benzodiazepine, dantrolene, and tizanidine. Chemoneurolysis of spasticity is done with botulinum toxin or a mixture of phenol and alcohol.

Discussion and Conclusion: Since muscle spasticity affects motor function and activities of daily living, understanding of this symptom and choosing an optimal treatment are necessary. Pharmacologic treatments should be administered with caution especially with the side effects. Optimal treatment of spasticity will bring the best neurological outcome for the patients.

Key Words: Muscle spasticity; Drug therapy; Motor activity; Activities of daily living

\section{서론}

경직은 1980년 Lance 등에 의해 처음 기술된 신경학적 장애의 하나로, 상위운동신경원병(upper motor neuron disease)의 양성 징후 중 하나이며, 추체로(pyramidal tract) 와 추체외로(extrapyramidal tract)의 병변과 연관된다[1,2].

Received: January 10, 2022 Accepted: January 17, 2022

Corresponding author: Dae-Yul Kim

E-mail: dykimsmart@gmail.com

(C) Korean Medical Association

This is an Open Access article distributed under the terms of the Creative Commons Attribution Non-Commercial License (http://creativecommons. org/licenses/by-nc/4.0) which permits unrestricted use, distribution, and reproduction in any medium, provided the original work is properly cited.
경직은 늘임반사(stretch reflex)의 과항진으로부터 초래 되며, 속도 의존성을 갖는 긴장성 늘임반사(tonic stretch reflex)의 증가와 건반사(tendon jerk)의 과항진을 특징으 로 하는 운동 장애이다[3]. 참고로 상위운동신경원병의 양 성 징후에는 경직성 근긴장이상증(spastic dystonia), 경직 성 동시수축(spastic co-contraction), 건반사의 과항진, 간 대(clonus) 등이 포함되고, 상위운동신경원병의 음성 징후에 는 근육 약화 및 피로가 포함된다[4].

경직은 특히 뇌나 척수 병변에서 발생하는 흔한 증상이 며, 일반적으로 처음 몇 시간 이내에서 몇 주 사이에 발생한 다[5]. Wissel 등의 연구[6]에 따르면 경직은 주로 팔꿈치(환 자의 $79 \%$, 손목 $(66 \%)$ 및 발목 $(66 \%)$ 에 영향을 미친다. 상지 경직의 가장 흔한 패턴은 내회전이며, 팔꿈치, 손목, 손가락 
Table 1. Modified Ashworth Scale and Modified Tardieu Scale

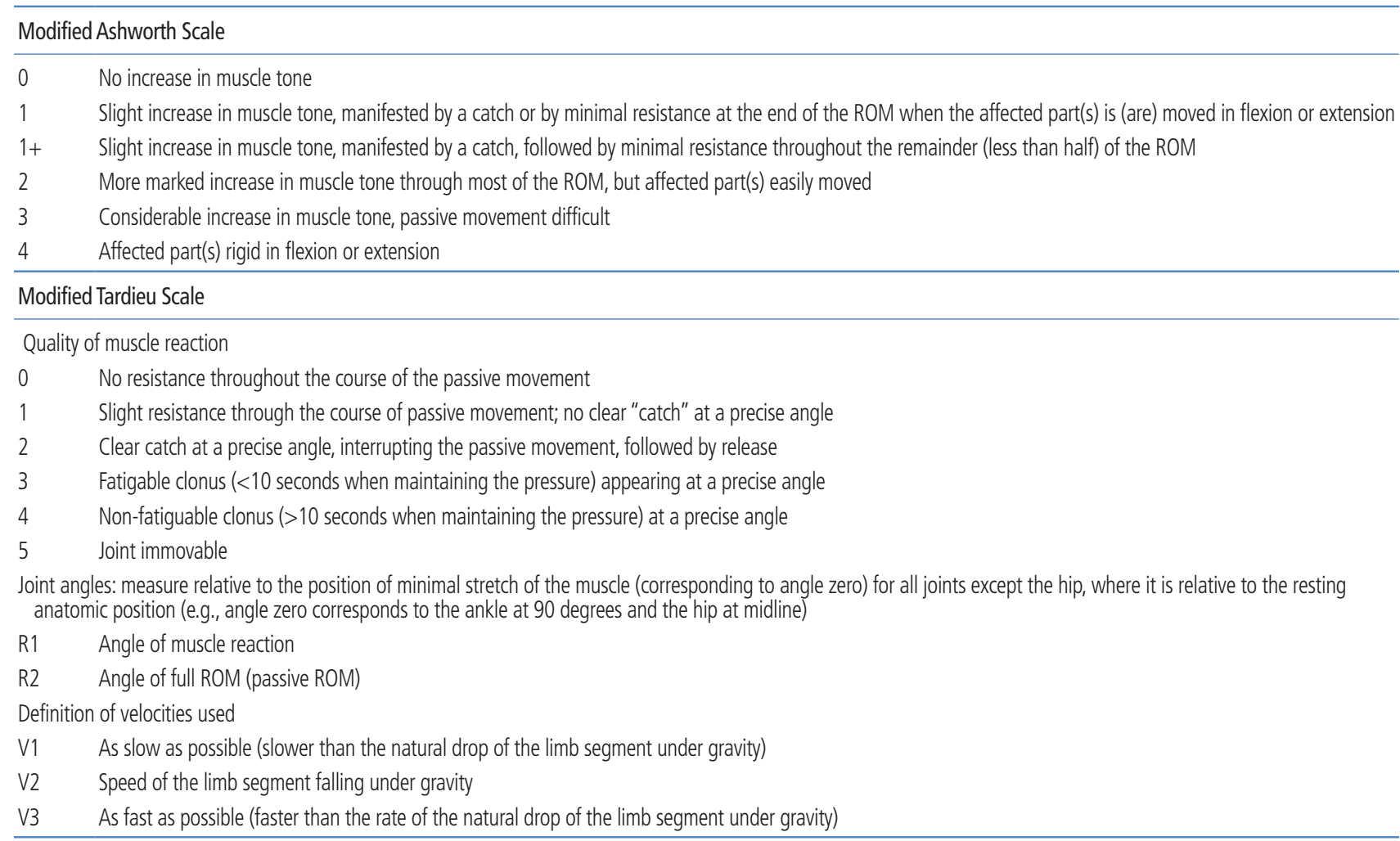

ROM, range of motion.

의 굴곡과 함께 어깨의 내전이 관찰된다[7]. 하지에서는 무 릎의 내전과 신전, 내반첨족이 가장 흔하게 관찰된다. 경직 은 통증, 관절 굳음(ankylosis), 건 수축(tendon retraction), 근육 위약을 유발할 수 있으며, 이는 성공적인 재활의 제한 점이 될 수 있다[8]. 또한 경직은 일상생활 동작과 삶의 질에 영향을 미친다.

이 논문에서는 경직의 평가에 대하여 간단히 살펴보고, 항 경직제의 기전과 특성 및 부작용에 대하여 살펴보고자 한다.

\section{경직의 평가}

경직의 평가에는 임상 척도 평가, 전기생리학적 평가, 생 역학적 평가를 포함하여 여러 가지 방법이 있지만, 가장 흔히 사용되는 방법은 임상 척도 평가이고, 이 중 수정 Ashworth 척도(Modified Ashworth Scale) [9]와 수정 Tardieu 척도 (Modified Tardieu Scale) [10]를 소개한다(Table 1).
수정 Ashworth 척도[9]는 1964년에 Ashworth가 개발한 5단계 척도를 1987 년 Bohannon과 Smith가 일부 수정하여 $\mathrm{I}$ 등급과 II등급 사이에 I+등급을 새로 추가한 척도이다. 수정 Ashworth 척도는 수동적 관절 움직임에 대한 저항 수준을 측정하는 방법이지만, Lance [3]의 정의한 경직에서와 같이 속도 의존성을 평가하지는 못한다. 이 평가방법은 쉽고 빠르 게 측정 가능하여 임상에서 효과적으로 사용 가능하다.

수정 Tardieu 척도[10]는 수정 Ashworth 척도와는 달리 수동적 관절 움직임에서의 속도, 수축이 발생하는 각도, 잠 재적인 힘줄 수축을 고려하기 때문에 Lance [3]의 경직 정의 에 더 가깝다. 이 척도에서는 관절을 빠르게 움직여서 측정 한 각도(R1)와 천천히 움직여 측정된 수정적 최대 관절운동 범위(R2)를 측정하고, 그 차이에 해당하는 부분이 경직의 동 적인 부분이 된다고 평가한다. 그 차이가 클수록 보툴리눔 독소(botulinum toxin) 등 치료의 효과가 클 것으로 예측할 수 있고, 그 차이가 적을수록 고정된 관절 구축이 많아 치료 의 효과가 적을 것으로 예측할 수 있다. 
Table 2. Dose, administration, mechanism, and side effects of the drugs

\begin{tabular}{|c|c|c|c|c|}
\hline Drug & Dose & Administration & Mechanism & Side effects \\
\hline Baclofen & $\begin{array}{l}\text { Adult: } 5-20 \mathrm{mg} \times 3 \text { times/day } \\
\text { Child: } 2.5 \mathrm{mg} / \mathrm{day} \sim 30-60 \mathrm{mg} / \mathrm{day}\end{array}$ & Oral & $\begin{array}{l}\text { Centrally acting GABA analogue; binds to } \\
\text { GABA } A_{B} \text { receptor at the presynaptic } \\
\text { terminal and inhibits the muscle stretch } \\
\text { reflex }\end{array}$ & $\begin{array}{l}\text { Sedation, dizziness, weakness, fatigue, } \\
\text { nausea, coma, respiratory difficulty, } \\
\text { lowers seizure threshold, baclofen } \\
\text { withdrawal syndrome }\end{array}$ \\
\hline Diazepam & $\begin{array}{l}\text { Adult: } 5-20 \mathrm{mg} \times 3-4 \text { times/day } \\
\text { Child: } 0.12-0.8 \mathrm{mg} / \mathrm{kg} / \mathrm{day}\end{array}$ & Oral & $\begin{array}{l}\text { Increases the affinity of GABA for the } \\
\mathrm{GABA}_{A} \text { receptor complex leading to an } \\
\text { increase in presynaptic inhibition and } \\
\text { reduction of synaptic reflexes }\end{array}$ & $\begin{array}{l}\text { Sedation, weakness, respiratory difficulty, } \\
\text { hypotension, adverse substance } \\
\text { dependence, ataxia, constipation, } \\
\text { voiding difficulty, saliva hypersecretion }\end{array}$ \\
\hline Dantrolene & $\begin{array}{l}\text { Adult: } 25-100 \mathrm{mg} \times 4 \text { times/day } \\
\text { Child: } 1-3 \mathrm{mg} / \mathrm{kg} \times 2-4 \text { times/day }\end{array}$ & Oral & $\begin{array}{l}\text { Interferes with the release of calcium from } \\
\text { the sarcoplasmic reticulum of the muscle }\end{array}$ & $\begin{array}{l}\text { Hepatotoxicity, muscle weakness, } \\
\text { sedation, dizziness, nausea, diarrhea }\end{array}$ \\
\hline Tizanidine & $\begin{array}{l}\text { Adult: } 4-36 \mathrm{mg} / \mathrm{day} \\
\text { Child: } 0.3-0.5 \mathrm{mg} / \mathrm{kg} / \mathrm{day}\end{array}$ & Oral & $\begin{array}{l}\text { Imidazole derivative, with agonist action } \\
\text { on alpha-2 adrenergic receptors in CNS }\end{array}$ & $\begin{array}{l}\text { Dry mouth, sedation, dizziness, mild } \\
\text { hypotension, weakness, dizziness, } \\
\text { hallucination, hepatotoxicity }\end{array}$ \\
\hline Botulinum toxin & $\begin{array}{l}\text { Adult: } 12 \text { units/kg } \\
\text { Child: } 16-20 \text { unit/kg (GMFCS level 1-4), } \\
\text { 12-16 unit/kg (GMFCS level 5) }\end{array}$ & Injectable & $\begin{array}{l}\text { Inhibit the release of } \\
\text { acetylcholine at the } \\
\text { neuromuscular junction }\end{array}$ & $\begin{array}{l}\text { Common cold like symptom, local } \\
\text { weakness, swallowing trouble for } \\
\text { patients with respiratory and } \\
\text { swallowing disorders }\end{array}$ \\
\hline Phenol/ alcohol & Adult: maximum $1 \mathrm{~g}(20 \mathrm{~mL}) 5 \%$ phenol & Injectable & Chemical denervation of the muscles & $\begin{array}{l}\text { Burning and dysesthesias, muscle } \\
\text { weakness, thrombosis, convulsion, CNS } \\
\text { depression, cardiovascular collapse }\end{array}$ \\
\hline Intrathecal baclofen & Start at $100 \mu \mathrm{g} /$ day & Intrathecal pump & $\begin{array}{l}\text { Binds to GABA receptor at the presynaptic } \\
\text { terminal and inhibits the muscle stretch } \\
\text { reflex }\end{array}$ & $\begin{array}{l}\text { CSF leakage, infection, pump } \\
\text { malfunction, sedation, muscle } \\
\text { hypotonia, respiratory difficulty, death }\end{array}$ \\
\hline
\end{tabular}

GABA, gamma-aminobutyric acid; CNS: Central Nervous System; GMFCS: Gross Motor Function Classification System.

\section{경직의 약물치료}

경직에 대한 치료는 경직으로 인한 장단점과 운동 장애 등의 기능 등 여러 가지를 고려하여, 꼭 필요할 때 시행한 다. 경직치료에는 물리치료, 작업치료, 보조기 및 보조기기 사용, 약물치료, 정형외과적 수술, 신경외과적 수술이 포함 된다. 물리치료와 작업치료를 기본으로 하되, 국소적인 경 직에서는 일반적으로 주사치료나 수술을 생각해볼 수 있 으며, 전신적인 경직에서는 약물치료를 고려해볼 수 있다. 이 논문에서는 약물치료에 대하여 더 자세히 알아볼 예정 이다.

경직은 중추신경계 손상에 의하여 척수 상부의 조절이 감 소하게 될 때 나타나므로, 이러한 신경계에 작용하는 신경전 달 물질을 목표로 약물치료를 하게 된다. 약물치료는 중추신 경계에 작용하거나 근육에 직접적으로 작용하여 근육의 긴 장도를 감소시키는데 목적이 있으며, 경구 또는 주사, 경막 내 펌프를 통하여 투여 가능하다. 각 약물의 기전 및 특성, 부작용에 대해서는 Table 2에 정리되어 있다.

\section{1. 경구투여약제}

현재 미국 식품의약국에 의해 공인된 약물은 baclofen, diazepam, dantrolene, tizanidine이다.

\section{1) Baclofen}

Baclofen은 gamma-aminobutyric acid (GABA) 작용제 로, 경직에 대하여 가장 많이 사용되는 약제이다. Baclofen 은 혈액뇌장벽(blood-brain barrier)을 통과하여 척수의 시 냅스 전 $\mathrm{GABA}_{\mathrm{B}}$ 수용체에 결합하여 근육 늘임반사를 억제한 다. 성인의 경우 $5 \mathrm{mg}$ 을 하루 3 회 복용으로 시작하여 3 일 간 격으로 5-10 mg씩 증가시켜 30-60 mg에서 일반적으로 경 직에 대한 효과를 보이게 된다. 최대 추천용량은 $80 \mathrm{mg}$ 이다 [11]. 소아는 하루 2.5-5 mg으로 시작하여 2-7세 소아에게 는 최대 $30 \mathrm{mg}$, 8세 이후에는 최대 $60 \mathrm{mg}$ 까지 사용할 수 있 다[12]. Baclofen은 진정, 피로 및 졸음과 같은 부작용이 있 으며[13,14], 과량투여 시 혼수 또는 호흡부전이 오기도 한 다. 경련의 역치 감소를 가져오기도 하고, 갑작스런 중단 시 baclofen 중단 증후군(baclofen withdrawal syndrome: 경 직 증가, 자율신경계 불안정성, 환각, 중추성 발열, 발작)을 가져올 수 있으므로 용량 감소 시 유의한다. 


\section{2) Benzodiazepine}

다이아제팜(diazepam) 또는 클로나제팜(clonazepam)과 같은 벤조다이아제핀(benzodiazepine)은 직접 GABA 수용 체에 부착하지는 않지만, 뇌간 망상체와 척수의 $\mathrm{GABA}_{\mathrm{A}}$ 수 용체복합체에 대한 GABA의 친화력을 높임으로써, 시냅스 전 단계의 억제를 증가시키고, 시냅스 반사를 감소시킨다. 다이아제팜은 성인의 경우 저녁에 $5 \mathrm{mg}$ 으로 시작하거나 2 $\mathrm{mg}$ 씩 하루 2회로 시작하여 증량하며 하루 3-4회 분할 투 여한다[11]. 보통 하루 15-60 mg의 용량에서 효과를 보인 다. 소아의 경우 하루 용량은 $0.12-0.8 \mathrm{mg} / \mathrm{kg}$ 로, 하루 최대 3-4회까지 분할하여 사용한다[12]. 이 약제는 근육의 과수 축을 줄여주지만, 근육 약화 및 졸음, 호흡억제, 저혈압을 유 발할 수 있다는 단점이 있다[15]. 운동실조, 변비, 배뇨장애, 침의 과다분비도 나타날 수 있다. 고용량 사용자에서 갑작스 럽게 중단하면 2-4일 후 약물 의존성(불안, 초조, 과흥분성, 근육경련, 오심, 불면, 고열, 광란, 사망 등)이 나타날 수 있 으므로 주의해야 한다. 클로나제팜은 다이아제팜보다 진정 작용이 덜하고 약물 의존성의 위험이 낮다는 장점이 있다.

\section{3) Dantrolene}

Dantrolene은 ryanodine 수용체에 결합하여, 근육 내의 근육세포질그물(sarcoplasmic reticulum)에서의 칼슘 방출 을 방해함으로써, 흥분/수축을 억제하여 경직을 줄인다. 이 러한 작용은 특히 골격근에서 주로 일어나고 중추신경계에 대한 작용 효과가 없기 때문에, 뇌졸중 등의 뇌손상 환자에 서 인지능력에 영향을 주지 않아 일차적으로 사용할 수 있다 는 견해가 있다[16]. 성인의 경우 초기 용량은 $25 \mathrm{mg}$ 으로 시 작하여 일주일 후 $25 \mathrm{mg}$ 씩 하루 3 회로 증량하고, 이후 25 $\mathrm{mg}$ 단위로 증량할 수 있는데, 최대 용량은 $400 \mathrm{mg} /$ day이 다[11]. 소아의 경우 1-3 mg/kg을 하루 2-4회 투여하며, 최대 용량은 $12 \mathrm{mg} / \mathrm{kg}$ 이다[12]. 부작용으로는 간독성이 있 어서 간질환이 있는 경우 금기이며, 이 밖에 근육 약화, 진 정, 어지러움, 설사 등이 있다.

\section{4) Tizanidine}

Tizanidine은 중추신경계에서 알파-2 아드레날린 수용체 작용제(agonist)로 작용하여 운동 뉴런의 시냅스 전 억제를 증가시킨다. 성인에서는 취침 전 $2 \mathrm{mg}$ 투약을 시작으로, 2
일마다 $2 \mathrm{mg}$ 씩 증량 가능하며, 최대 용량은 $36 \mathrm{mg} /$ day까지 가능하다[11]. 소아에서는 10 세 미만의 경우 취침 전 $1 \mathrm{mg}$ 투약을 시작으로 일주일 간격으로 증량하여 $0.3-0.5 \mathrm{mg} /$ $\mathrm{kg}$ 을 하루 4 회 나누어 복용한다. 10 세 이상의 경우 취침 전 $2 \mathrm{mg}$ 투약으로 시작한다[12]. 부작용으로는 입 마름, 진정, 저혈압, 무력증, 어지러움, 환각, 간독성 등이 있다[17].

\section{2. 화학적 신경차단술}

화학적 신경차단술(chemoneurolysis)에는 보툴리눔 독소 주사요법과 페놀/알코올을 이용하는 신경차단술 또는 운동 점(motor point) 차단술이 포함된다. 이는 경직이 있는 부위 에 국한하여 경직을 감소시킬 수 있다는 장점이 있다. 두 가 지 치료방법의 작용 기전은 다르지만, 공통적으로 화학적 탈 신경을 일으켜 경직을 야기하는 근육의 수축을 억제함으로 써 경직을 완화시킨다.

\section{1) 보툴리눔 독소 주사요법}

보툴리눔 독소 주사요법은 근육 내 주사로 투여되며, 주로 국소 경직이 있을 때 선택하는 치료방법으로, 신경 근육접합부(neuromuscular junction)에서 아세틸콜린 (acetylcholine) 방출을 억제하여 근육의 수축을 감소시킨다 [18]. 그 효과는 주사 수일 후에 시작되어 3-6개월 정도 지 속하는 가역적인 마비로 경직 감소 효과를 나타낸다. 중화항 체 형성에 대한 위험으로 3 개월 이내의 보툴리눔 독소의 재 투여는 피하는 것이 좋다. 보툴리눔 독소 주사요법은 페놀이 나 알코올에 비하여 적정 및 투여가 용이하기 때문에 더 많 이 사용된다[15]. 성인에서의 용량은 onabotulinum toxin A (Botox, Allergan Inc., Irvine, CA, USA) 기준으로 12 unit $/ \mathrm{kg}$, 시술 한번 당 360 unit이며, 소아의 경우 뇌성마비 대운동분류(Gross Motor Function Classification System, GMFCS) 1-4의 경우 16-20 unit $/ \mathrm{kg}$, 대운동분류 5의 경우 12-16unit $/ \mathrm{kg}$ 을 사용하는 것이 일반적이다[11]. 치료가 필 요한 근육을 정확하게 주사하기 위하여 표면 해부학, 전기 자극, 초음파 등을 이용할 수 있다[19]. 이 치료방법을 이용 하여 팔꿈치, 손목, 손가락 등의 상지[20,21] 및 발과 종아 리 등의 하지[22] 긴장도를 효과적으로 줄일 수 있으며, 환 자들의 능동적 움직임의 증가와 자가관리, 걷기 등의 자율성 
의 증가를 가져왔다는 보고가 있다[20]. 보툴리눔 독소 주사 요법은 근긴장도를 줄이고 물리치료의 효과를 증가시키는 것 이외에도, 진통의 효과도 일부 가져올 수 있다[23]. 보툴 리눔 독소 주사요법의 부작용으로는 주사 직후 감기 유사 증 상, 근육의 약화, 연하장애가 있는 환자에서 연하장애의 악 화가 있을 수 있다[19]. 금기증으로는 근무력증과 같은 신경 근육접합부의 질환, 혈액 응고 질환, 독소에 알레르기가 있 는 경우 등이 있다.

\section{2) 페놀/알코올 신경차단술}

페놀과 알코올은 신경용해제(neurolytic agent)로, 단백질 을 변성시켜 화학적으로 탈신경화를 유도할 수 있다. 보툴 리눔 독소 주사와 비교하였을 때, 효과는 9-12개월 정도로 더 오래 지속된다[11]. 권장 농도는 5\% 페놀과 45-100\% 알 코올이 가장 많이 사용되며, 성인의 경우 하루 최대 $1 \mathrm{~g}$ (20 $\mathrm{mL})$ 의 $5 \%$ 페놀이 사용 가능하다[12]. 소아의 경우 적절한 용량에 대하여 알려진 바가 없다. 일반적으로는 전기자극기 를 사용하여 원하는 신경 혹은 운동점을 찾아서 주사하며, 최근에는 초음파 유도하에서 시도되기도 한다. 부작용으로 는 작열통, 원하지 않은 부위의 근위약, 혈전 형성, 혈관 내 주사 부작용(경련, 중추신경계 기능 감소, 심장혈관계 쇠약) 등의 부작용이 발생할 수 있다[24].

\section{3. 경막 내 바클로펜 펌프}

경막 내 바클로펜 펌프(intrathecal baclofen pump, ITP) 는 $\mathrm{GABA}$ 작용제를 척수에 직접적으로 투여하여 경직을 완 화할 수 있으며, 부작용은 최소화할 수 있는 방법이다. 이 치료방법의 고려 대상은 일상생활 동작에 많은 영향을 주 는 Modified Ashworth Scale 2 이상의 심한 하지 경직, 기 존의 경직치료로 충분하지 않은 경직 조절, ITP의 주의지침 을 이해하고 따를 수 있는 환자와 보호자이다[11]. 펌프의 크 기 때문에 일반적으로 4 세 이상, 체중 $15 \mathrm{~kg}$ 이상에서 수술 이 가능하였지만, 작은 펌프의 개발 이후 이러한 제한이 다 소 완화되었다[12]. 일반적으로 ITP trial을 먼저 시행하고 효과가 있는 경우 치료방법으로 채택하며, 투약 용량은 대 개 $100 \mathrm{\mu g} / \mathrm{day}$ 로 시작하여 10-20\% 간격으로 매우 신중하 게 증량한다. 부작용으로는 뇌척수액 누출, 감염, 도관의 고
장 등의 수술 혹은 기기와 관련된 것이 있으며, 과다 투여의 경우에는 의식 저하, 근육긴장 저하, 호흡곤란, 사망까지 발 생할 수 있다[25].

\section{결론}

경직은 운동기능 및 일상생활에 영향을 미치기 때문에 경 직에 대한 이해 및 치료는 필수적이다. 경직의 범위 및 중증 도에 따라서 경직에 대한 약물치료 및 투여방법(경구, 주사, 경막 내 펌프)을 선택할 수 있으며, 각 약물치료에 대한 부작 용에 대해서도 주의가 필요하다. 환자의 경직의 정도는 변할 수 있기 때문에 늘 최적의 치료에 대하여 고민이 필요하며, 장기간의 약물치료는 습관화를 가져올 수 있기 때문에 주의 가 필요하다. 최적의 경직치료는 환자에게 최상의 신경학적 인 결과를 가져올 수 있을 것이다.

찾아보기말: 근육경직; 약물요법; 운동능력; 일상활동

\section{ORCID}

Eun Jae Ko, https://orcid.org/0000-0001-7198-5407

Dae-Yul Kim, https://orcid.org/0000-0003-1275-1736

\section{Conflict of Interest}

No potential conflict of interest relevant to this article was reported.

\section{References}

1. Feldman RG, Young RR, Koella WP. Spasticity: disorders motor control. Chicago: Year Book Medical Publishers; 1980.

2. Pandyan AD, Gregoric M, Barnes MP, Wood D, Van Wijck F, Burridge J, Hermens H, Johnson GR. Spasticity: clinical perceptions, neurological realities and meaningful measurement. Disabil Rehabil 2005;27:2-6.

3. Lance JW. Pathophysiology of spasticity and clinical experience with Baclofen. In: Feldman RG, Young RR, Koella 
WP; CIBA-GEIGY Corporation, editors. Spasticity: disordered motor control. Chicago: Year Book Medical Publishers; 1980. p. 185-204.

4. Soyuer F, Ozturk A. The effect of spasticity, sense and walking aids in falls of people after chronic stroke. Disabil Rehabil 2007;29:679-687.

5. Mayer NH, Esquenazi A. Muscle overactivity and movement dysfunction in the upper motoneuron syndrome. Phys Med Rehabil Clin N Am 2003;14:855-883.

6. Wissel J, Schelosky LD, Scott J, Christe W, Faiss JH, Mueller J. Early development of spasticity following stroke: a prospective, observational trial. J Neurol 2010;257:1067-1072.

7. Hefter H, Jost WH, Reissig A, Zakine B, Bakheit AM, Wissel J. Classification of posture in poststroke upper limb spasticity: a potential decision tool for botulinum toxin A treatment? Int J Rehabil Res 2012;35:227-233.

8. Duncan PW, Zorowitz R, Bates B, Choi JY, Glasberg JJ, Graham GD, Katz RC, Lamberty K, Reker D. Management of adult stroke rehabilitation care: a clinical practice guideline. Stroke 2005;36:e100-e143.

9. Bohannon RW, Smith MB. Interrater reliability of a modified Ashworth scale of muscle spasticity. Phys Ther 1987;67:206-207.

10. Tardieu G, Shentoub S, Delarue R. [Research on a technic for measurement of spasticity]. Rev Neurol (Paris) 1954;91:143144. French.

11. The Korean Academy of Rehabilitation Medicine. Rehabilitation medicine. Paju: Koonja; 2020.

12. Korean Society of Pediatric Rehabilitation and Developmental Medicine. Pediatric rehabilitation. 3rd ed. Paju: Koonja; 2021.

13. Hulme A, MacLennan WJ, Ritchie RT, John VA, Shotton PA. Baclofen in the elderly stroke patient its side-effects and pharmacokinetics. Eur J Clin Pharmacol 1985;29:467-469.

14. Goldstein EM. Spasticity management: an overview. J Child Neurol 2001;16:16-23.

15. Lapeyre E, Kuks JB, Meijler WJ. Spasticity: revisiting the role and the individual value of several pharmacological treatments. NeuroRehabilitation 2010;27:193-200.

16. Zhao F, Li P, Chen SR, Louis CF, Fruen BR. Dantrolene inhibition of ryanodine receptor $\mathrm{Ca} 2+$ release channels. Molecular mechanism and isoform selectivity. J Biol Chem 2001;276:13810-13816.

17. Quality Standards Subcommittee of the American Academy of Neurology and the Practice Committee of the Child Neurology Society, Delgado MR, Hirtz D, Aisen M, Ashwal S, Fehlings DL, McLaughlin J, Morrison LA, Shrader MW, Tilton A, Vargus-Adams J. Practice parameter: pharmacologic treatment of spasticity in children and adolescents with cerebral palsy (an evidence-based review): report of the Quality Standards Subcommittee of the American Academy of Neurology and the Practice Committee of the Child Neurology Society. Neurology 2010;74:336-343.

18. Yelnik AP, Simon O, Bensmail D, Chaleat-Valayer E, Decq P, Dehail P, Quentin V, Marque P, Parratte B, Pellas F, Rousseaux M, Trocello JM, Uzzan M, Dumarcet N; Agence francaise de securite sanitaire des produits de sante. Drug treatments for spasticity. Ann Phys Rehabil Med 2009;52:746-756.

19. Sheean G, Lannin NA, Turner-Stokes L, Rawicki B, Snow BJ; Cerebral Palsy Institute. Botulinum toxin assessment, intervention and after-care for upper limb hypertonicity in adults: international consensus statement. Eur J Neurol 2010;17 Suppl 2:74-93.

20. McCrory P, Turner-Stokes L, Baguley IJ, De Graaff S, Katrak P, Sandanam J, Davies L, Munns M, Hughes A. Botulinum toxin A for treatment of upper limb spasticity following stroke: a multi-centre randomized placebo-controlled study of the effects on quality of life and other person-centred outcomes. J Rehabil Med 2009;41:536-544.

21. Bakheit AM, Thilmann AF, Ward AB, Poewe W, Wissel J, Muller J, Benecke R, Collin C, Muller F, Ward CD, Neumann C. A randomized, double-blind, placebo-controlled, doseranging study to compare the efficacy and safety of three doses of botulinum toxin type A (Dysport) with placebo in upper limb spasticity after stroke. Stroke 2000;31:2402-2406.

22. Burbaud P, Wiart L, Dubos JL, Gaujard E, Debelleix X, Joseph PA, Mazaux JM, Bioulac B, Barat M, Lagueny A. A randomised, double blind, placebo controlled trial of botulinum toxin in the treatment of spastic foot in hemiparetic patients. J Neurol Neurosurg Psychiatry 1996;61:265-269.

23. Pedreira G, Cardoso E, Melo A. Botulinum toxin type A for refractory post-stroke shoulder pain. Arq Neuropsiquiatr 2008;66:213-215.

24. Elovic EP, Esquenazi A, Alter KE, Lin JL, Alfaro A, Kaelin DL. Chemodenervation and nerve blocks in the diagnosis and management of spasticity and muscle overactivity. PM R 2009;1:842-851.

25. Stempien L, Tsai T. Intrathecal baclofen pump use for spasticity: a clinical survey. Am J Phys Med Rehabil 2000; 79:536-541.

\section{Peer Reviewers' Commentary}

이 논문은 뇌질환이나 척수손상 등 중추신경계 손상 이후 발생하 는 가장 흔한 문제점인 경직의 약물치료에 대한 최신문헌을 정리 하여 설명해 주고 있다. 경직은 통증 및 관절 구축, 근위약 등 불 편한 신체적 증상을 일으킬 뿐 아니라 식사하기, 옷 입기, 용변 보 기 등 기본적인 일상생활 동작 수행 능력과 보행 기능에도 큰 영 향을 미치기 때문에 적극적인 치료가 필요하다. 이 논문에서는 임 상에서 경직을 쉽게 평가할 수 있는 임상 척도들을 소개하고 있 으며, 특히, 다양한 항경직 약제들을 성인과 소아에서의 적절한 처방 용량, 특장점과 부작용 등을 잘 정리하여 기술하고 있다. 이 논문은 경직이 발생한 환자를 진료하는 임상 현장에 많은 도움이 될 것으로 판단된다.

[정리: 편집위원회] 